\title{
Agustín Edwards Eastman: una biografia desclasificada del dueño de El Mercurio Víctor Herrero A.
}

Penguin Random House Grupo Editorial S.A. 2014, Santiago, 620 págs.

\section{Dimas Floriani}

Coordenador acadêmico da Rede CASLA-CEPIAL, Curitiba, Brasil.

Email: dimas@casla.com.br

Em seu alentado livro, publicado em novembro de 2014 em Santiago de Chile, o jornalista e pesquisador Victor HerreroAguayo nos apresenta uma competente biografia sobre Agustín Edwards Eastman.

O subtítulo "uma biografia desclassificada do dono do El Mercurio" poderia dar margem à ambiguidade, não fosse o sentido de ‘desclassificado' que é aplicado aos documentos de inteligência do governo norte-americano e tornados públicos para pesquisa e demais consultas. Esta fonte documental é muito importante para o autor, em termos de fontes de documentação sobre as quais reconstitui a história política do Chile, o envolvimento do Pentágono e demais atores econômicos e políticos norteamericanos estrategicamente envolvidos nos principais episódios das crises que marcaram o país, especialmente desde os anos 1960 a 2000.

O fio condutor dessa biografiaé a dinastia dos Edwards, vinculada aos negócios financeiros - banco e seguradora -, da indústria de transformação, da mineração,fundadores do El Mercurio em 1900 e personagens centrais da história política, econômica e social daquele país.

O objetivo do livro é traçar o perfil dos cincoAgustín Edwards e que para diferenciar um do outro incluem o nome materno, como é de costume em países de tradição hispânica. A ênfase da pesquisa, contudo, é dada para a trajetória de Agustín Edwards 5º (1927-___), o Doonie (este era seu apelido)e que traz como sobrenome Eastman, por parte da mãe, pois foi o principal personagem da história do envolvimento político do El Mercurio, contada em detalhes, cobrindo dois momentos cruciais da democracia (governos Eduardo Frei Montalva e Salvador Allende Gossens, de 19651973) e da ditadura do General Pinochet (1973-1990).

A tradição inglesa do sobrenome da família estaria ligada à chegada de um viajante britânico, não se sabe ao certo se aventureiro ou 
plebeu,George Edwards, tendo chegado às costas de Coquimbo em 1804 na região central do país, trinta e dois anos antes de Charles Darwin passar pela ilha de Chiloé. George Edwards acabou casando com Isabel Ossandón Iribarren, filha de um fazendeiro de La Serena.

O livro de mais de 600 páginas tem como objetivo fazer uma recomposição histórica da família Edwards, uma espécie de história da elite e da oligarquia chilena. A origem inglesa do sobrenome da família é uma espécie de amuleto que não serve apenas para manter a tradição da família, mas que se traduz nas experiências de cada um desses representantes dinásticos, ao manter seus vínculos comerciais, intelectuais, culturais e políticos com a City, inicialmente, e posteriormente com Paris e Nova York.

Agustín Edwards Eastman (Doonie), nasceu em 1927 em Paris, filho de Agustín Edwards Budge e de María Isabel Eastman Beeche e neto de Agustín Edwards Mac Clure. De rápido retorno ao Chile, embarcou novamente com seus pais e avô para Londres, pois este era amigo pessoal do Presidente Arturo Alessandri Palma (presidente por duas ocasiões: 192025 e 1932-38) que o designou como embaixador chileno na Inglaterra, onde Doonie receberia boa parte de sua formação escolar primária. De retorno a Santiago em 1937, conclui seus estudos secundários em colégio de língua e cultura inglesa; posteriormente ingressa no curso de direito na Universidad Católica de Chile, mas não chega a concluí-lo.

A exemplo de seu avô e do seu pai, que sempre combinaram negócios com jornalismo, Doonie começa suas experiências jornalísticas pouco antes de terminada a II Guerra Mundial, dedicando-se a temas de política internacional.

Em 1947 vai cursar em Princeton, EUA, o Instituto de Assuntos Públicos e Internacionais, atualmente chamado de Woodrow Wilson School of Public and International Affairs. Em 1949 apresenta sua monografia em inglês com o título de Anarchy and Autocracy. Chile 1817 to 1831.

Sua experiência nos EUA é significativa por algumas razões, o que marcará a posteridade de suas experiências com aquele país e com a visão política conservadora que desenvolverá sobre a história do Chile. Um de seus colegas no Instituto de Princeton foi Paul Volcker, economista que entre 1979 e 1987 foi presidente do Federal Reserve Bank,o Banco Central norte-americano. O contato privilegiado com a elite intelectual, econômica e política norte-americana seria uma faceta duradoura na forma de estabelecer vínculos e compromissos com os interesses estratégicos norte-americanos no Chile e na América Latina, pela amizade pessoal que Doonie mantinha com o magnata David Rockfeller, e com o dono da Pepsi-Cola Donald Kendall, que possuíam canal direto com o Pentágono, especialmente com os republicanos; Kendall lhe ofereceu o posto de vice-presidente internacional da empresa, em Connecticut, quando Dooniese auto exilou do Chileem 1970, com a vitória de Salvador Allende nas eleições presidenciais. 
Em relação ao título de sua monografia, ela não é tão inocente e distanciada da época contemporânea de sua formação, pois Doonie sempre reivindicava para a linha editorial do El Mercurio uma postura adotada por Diego Portales ${ }^{1}$, dirigente conservador do século XIX no Chile, sob o lema de "mudança na ordem”, figura tão cara aos generais golpistas de 1973; não por acaso, a Junta Militar instalou-se logo após o golpe de 11 de setembro no Edifício da UNCTAD, inaugurada por Allende em 1972, onde hoje é o Centro Cultural Gabriela Mistral (GAM), e na época batizada pelos militares como Palácio Diego Portales.

Ainda em 1901, seu avô, Agustín Edwards Mac Clure, fundador do El Mercurio (1900) havia viajado aos EUA, entusiasmado com as suas técnicas comerciais e tecnológicas na produção de jornais; duas décadas depois, por volta de 1920 retorna para atualizar-se com o sistema de extração e processamento de salitre que prometia reduzir em 40 por cento os custos de produção. A família Guggenheim, que participava do cartel do salitre e de outras empresas de cobre, vende para Anaconda Copper Mining Company uma participação majoritária da maior mina de céu aberto do mundo Chuquicamata, nacionalizada 50 anos depois pelo governo da Unidade Popular.

A história do clã dos Edwards está recheada de investimentos de exploração dos recursos minerais, associações comerciais, industriais e financeiras, com capitais nacionais e internacionais, especialmente com empresas norte-americanas. Simultaneamente, esses negócios eram politicamente monitorados com os governantes de turno, ideologicamente temperados pela formação de uma opinião pública conservadora, desde a imprensa nacional controlada em todas as principais cidades do país por El Mercurio que havia adquirido os principais jornais regionais do país.

"El Mercurio foi um dos primeiros meios a unir-se à Sociedade Interamericana de Imprensa (SIP), uma organização fundada em 1943 em Havana e que reunia os donos e altos executivos dos principais jornais da América Latina. Em pouco tempo, a SIP passaria a ter sede permanente nos Estados Unidos e a converter-se em um dos principais veículos para influenciar a opinião pública latino-americana, em especial para divulgar campanhas anticomunistas e louvar a liberdade de expressão, como um dos maiores valores da democracia liberal”. (HERRERO AGUAYO, V. op. cit, p. 157)².

A imprensa conservadora e monopólica brasileira também fez e faz parte da SIP, bastião da Guerra Fria contra a ameaça de governos reformistas, populistas e revolucionáriosno século XX. Sob a alegação de ameaça à liberdade de imprensa, O Globo, o Estado de São Paulo, a Revista Veja, principalmente, fazem uma cruzada permanente de denúncia contra os governos atuais da Argentina, Bolívia, Brasil, Equador e Uruguai por quererem impor um marco regulatório ao poder privado da mídia.

Com o falecimento prematuro do pai Agustín Edwards Budge, em 1956, Doonie, o Agustín $5^{\circ}$.,torna-se o herdeiro principal da dinastia e dos 
negócios da família, com apenas 29 anos de idade, período em que tomará para si a gestão e a condução estratégica na diretoria do principal jornal do país. Uma vez mais, a cultura jurídica do primogênito (mayorazgo) se impunha na sucessão dos negócios da dinastia.

A história que segue na formação de uma equipe de colaboradores do jornal, tem sua origem na criação, em meados dos anos 60, do CESEC (Centro de EstudiosSocio-Económicos), o primeiro think tank do pensamento conservador da sociedade chilena, para contrapor-se à visão estatista e socialdemocrata de partidos de centro e centro-esquerda que vinham sucessivamente disputando a presidência do Chile, desde 1958. Doonie e seus colaboradores forjarão as bases de um novo pensamento econômico, vinculado à matriz neoliberal da Escola de Chicago, em torno a economistas vinculados à Universidad Católica de Chile. Neste sentido, essa matriz de pensamento encontraria eco e abrigo, logo em seguida,na ditadura militar.

O livro de Herrero Aguayo traz novidades em sua segunda parte ( $A l$ Mando Del Imperio: 1956-1969), em que são revelados episódios pouco conhecidos entre Agustín Edwards Eastman e os EUA, com a surpreendente colaboração entre El Mercurio e a CIA. Doonie acabou apoiando a candidatura de Eduardo Frei Montalva contra Salvador Allende nas eleições de 1964. Essa colaboração se intensificaria com a vitória de Allende nas eleições de 1970 .

Contudo, o que chama atenção na trajetória de Edwards é a rede social que desenvolveu com diversos atores econômicos, políticos e com estamentos militares, especialmente com a Marinha, consolidando suas afinidades eletivas em relação às suas escolhas ideológicas e políticas. Em 1967, juntamente com Hernán Cubillos, Roberto Kelly, José Toribio Merino, todos golpistas em 1973, fundam uma sociedade de amantes de esportes marinhos (Cofradía Náutica).

Chama atenção também o fato de que a fortuna da dinastia, em mãos de Doonie, sofreu diversos percalços ao longo de seu reinado, perdendo duas vezes a propriedade do Banco Edwards e quase falindo a empresa $E$ l Mercurio, não fosse a mão amiga do ditador Pinochet que anistiou importante parcela de seu endividamento junto ao Banco do Estado: "o apoio político irrestrito que El Mercurio dispensou à ditadura até seu último dia no poder, assim como nas seguintes duas décadas ao defender o legado institucional de reformas econômicas do regime de Pinochet, foi em parte o agradecimento de Agustín Edwards por tê-lo salvo em repetidas ocasiões da ruína financeira. (...) para Agustín Edwards e muitos outros representantes da tradicional oligarquia chilena, os quase dezessete anos de Pinochet não foram uma ditadura, porém a encarnação de um novo regime portaliano” (op.cit. p. 468).

Na quinta e última parte do livro (Construyendo uma nueva identidad: 1990-2012) Agustín Edwards se reinventa, tanto na maneira de 
convivência com os governos da Concertación, aproximando diversas personalidades políticas e empresariais em torno da Fundação Paz Ciudadana, como no domínio de seus investimentos, agora com uma estratégia de capitalista agrário, voltado à aquisição de terras para a criação de bovinos de carne de corte para exportação e de cavalos de raça. Nada melhor do que lançar raízes na terra, para sentir-se meio huaso, uma vez que sempre foi visto como meio chileno por conta de sua estirpe inglesa!

Além desta biografia nos indicar uma metodologia interessante para entender como se constroem fortunas na América Latina, associadas às trajetórias de oligarquias e dinastias familiares dos 'senhores da imprensa', profundamente implicados com o poder e a ordem conservadora, esta obra lança desafios para imaginar o que seria uma imprensa alternativa, a partir de um marco regulatório democrático e anti-monopolista, em que se possa receber uma informação política e ideologicamente pluralista e não a reserva ideológica de uma elite conservadora, autoritária e repressora dos anseios de uma nova ordem autenticamente democrática na América Latina. 
Polis, Revista Latinoamericana, Volumen 15, $N^{\circ}$ 44, 2016

\section{Notas}

${ }^{1}$ [Diego Portales]Lideró políticamente las fuerzas conservadoras en la Guerra Civil de 1829-1830 y, tras rehusar la presidencia de la República, colaboró con el gobierno de Joaquín Prieto aplicando duras medidas, que incluían destierros y fusilamientos de los opositores al régimen, para imponer el orden. (http://es.wikipedia.org/wiki/ Diego_Portales).

2 “El Mercurio desempeñó una función de información y dirección ideológica de la clase dirigente en su conjunto, a la vez que ejerció una influencia incomensurable también en los sectores medios y en los poderes públicos” (op. cit. P. 167, apud Sofía Correa Sutil, (2004). Con las riendas del poder. La derecha chilena en el siglo XX, p. $54)$. 